\title{
Biomaterials: Role of surface modifications
}

\author{
CHANDRA P SHARMA
}

Biosurface Technology Division, Biomedical Technology Wing, Sree Chitra Tirunal Institute for Medical Sciences and Technology. Trivandrum 695012, India

\begin{abstract}
The fundamental concepts related to biomaterials and blood/tissue-material interactions at the interface have been reviewed. The relevance of surface modification to enhance blood and/or tissue compatibility of materials has been discussed and its role in selected prosthetic applications described.
\end{abstract}

Keywords. Biomaterial; surface modification; protein adsorption; blood compatibility; tissue compatibility; calcification; hemoperfusion; artificial skin.

\section{Introduction}

When one looks at the intima of a blood vessel, it appears hydrated, gelatinous, flexible and multiphase to prevent protein and platelet reactions with its carbohydraterich outer coat (Rigby 1961). Further, on closer investigation, one will find a definite arrangement of endothelial cells having specific physiological responses, even secreting pharmacologically active substances such as prostaglandin $\mathrm{PGI}_{2}$ possessing antiplatelet activity by stimulating membrane-bound adenyl cyclase and thereby raising the intracellular levels of cyclic AMP (cAMP) within platelets (Moncada and Vane 1979; Bonne et al 1981). Thus the intima's complex role of keeping the blood flowing in living blood vessels makes it impossible to duplicate it by any artificial means. Attempts have been made by grafting hydrogels, developing textures or microdomain structures, or hydrophobic-hydrophilic optimization on polyurethane substrates (Sharma 1991) to enhance blood compatibility. Negative surface charge (Sawyer 1985) and even electrical conduction and semiconduction properties based on specific structural regularity of various proteins and polymers also seem to play a role in enhancing blood compatibility (Bruck 1979).

Scientific efforts have been made to immobilize covalently (or facilitate controlled release of) the selected bioactive molecules such as $\mathrm{PGI}_{2}, \mathrm{PGE}_{1}$, phosphorylcholine, heparin, hirudin, urokinase or streptokinase, antithrombin III, cAMP collagen, etc and their complexes with albumin onto the substrates along with oral antiplatelet drugs like aspirin; vitamins C, E, B 6 ; antibiotics; etc (Sharma 1991). It seems that antiplatelet biomolecules preferentially promote albumin adsorption. Efforts have also been made to graft heparinoid polyelectrolyte, synthesized in our laboratory from natural rubber on polyetherurethane urea (PEUU) surfaces. These surfaces have a marked effect in decreasing platelet adhesion with minimal protein interaction, and can act as a passive layer enhancing blood compatibility (Sharma and Nair 1984). It has also been found that surfaces adsorbing more high-density lipoprotein (HDL) compared to low-density lipoprotein (LDL) are relatively more bloodcompatible (Chandy and Sharma 1991). Endothelialization of porous substrates via cell culture technique with coimmobilization of cell-growth and cell-adhesive factors has also been tried (Ito 1992). However, the problem of immune response and steady supply of cells is not fully solved. Genetically engineered endothelial cells have been 
seeded on fibronectin-coated vascular grafts to secrete increased amounts of tissue plasminogen activator enhancing thromboresistance. The production of plasminogen activator has been found to be higher on collagen-impregnated Dacron than on expanded poly(tetrafluoroethylene) (PTFE) or polyurethane/Dacron composite (Shayani et al 1992). Pentapeptides have been used to form an elastic matrix via crosslinking by gamma irradiation and addition of fibronectin for cell attachment. Fibroblasts, endothelial cells and other cells have been used for such studies (Urry et al 1992). Even a composite graft made of polyurethane-coated pericardium has been developed (Tolia and Sharma 1986), with all these efforts there is still no small-diameter vascular graft $(<5 \mathrm{~mm}$ diameter) available today except sephanous vein to replace coronary artery without thrombus formation. Attempts have been made to develop small-diameter vessels from PEUU. However, in in vivo trials in mongrel dogs at iliac artery, the graft showed thrombus formation initiated from the suture site at the anastomosis within 20 days (Sharma 1983). Therefore the core of our discussion here is related to the surface energy parameters and the necessity of optimizing them with biophysicochemical aspects comprehensively for understanding the blood/tissue-material interactions at the interface.

\section{Background}

Any nonliving materials used in a medical device intended to interact with biological systems is called a biomaterial (Williams 1987). Obviously it should be nontoxic, fabricable, sterilizable, and stable during implantation and as required by application. It should not corrode, degrade, or be carcinogenic. Further the ability of a material to perform with an appropriate host response in a specific application is termed biocompatibility. This is controlled at tissue-material interfaces by pore size and density (soft tissue $\approx 50 \mu$, hard tissue (bone) $>100 \mu$ ), geometrical nature, controlled chemical breakdown by the resorption of material where material may be replaced by regenerating tissue, and controlled surface reactivity. If the surface reactivity is high, usually healing is delayed by formation of giant cells, and the fibrous tissue layer is much thicker causing tissue instability. Some of the tissue-compatible materials (materials used in contact with tissue) are titanium, cobalt-chromium alloy, bioglass, aluminium oxide, hydroxylapatite, chitosan, etc.

Ideal blood-compatible materials (materials used in contact with blood) do not activate the intrinsic blood coagulation system or to attract or alter platelets or leucocytes (Forbes and Prentice 1978). Blood compatibility of any material is dependent on surface charge, surface free energy, chemical group distribution, heterogenicity, surface texture, porosity, smoothness and flow conditions. International efforts continue towards production of materials that prevent thrombosis, surface modification to enhance blood compatibility, and use of therapeutic substances that prevent deposition of fibrin. Some of the commonly used blood-compatible materials are polydimethylsiloxane, cellulose acetate, polyacrylonitrile, PTFE, nylon, polycarbonate, polyurethane, poly(methyl methacrylate) (PMMA), pyrolytic and low-temperature isotropic (LTI) carbons, etc.

\section{Theory and experimental}

When any material comes in contact with blood instant adsorption of proteins takes place with a certain selectivity, rate and concentration. The interaction involves 
intermolecular forces which develop at the interface, e.g. London dispersion forces, hydrogen bonds, dipole-dipole interactions, donor-acceptor bonds, electrostatic interactions, acid-base interactions, etc. Albumin-coated surfaces do not seem to attract platelets (Lyman et al 1968; Kim and Lyman 1973), whereas $\gamma$-globulin and fibrinogen coatings cause not only platelet adhesion but also aggregation and release of platelet constituents (Vroman and Adams 1971). The processing parameters also can change the nature of the adsorbed proteins due to variations in microstructure; for example, the glass side and air side of cast polyurethane urea with polypropylene glycol (MW 1025) are found to be different as the air-side domain size is $80-120 \AA$ and the glass-side size $30-50 \AA$ (Sharma 1980).

When blood comes in contact with any material it probably involves the following steps (Vroman 1984-85) in the intrinsic system as follows:

(i) The factor XII protein (Hageman factor) adsorbed onto the surface becomes activated and this (XIIa) activates other molecules of XII.

(ii) The molecules of high-molecular-weight kininogen (HMWK) carrying factor XI are adsorbed near factor XIIa, along with other molecules of HMWK carrying prekallikrein.

(iii) Factor XIIa activates factor XI to factor XIa and converts prekallikrein to kallikrein.

(iv) Kallikrein can activate more factor XII.

(v) With the activation of factor XIa the fluid phase of clotting with the requirement of calcium ion begins with further activation of factor IX to IXa.

(vi) The $\gamma$-carboxyglutamic acid groups and the negatively charged groups on the phospholipid droplets with calcium ions as bridges, factor IXa comes closer to factor VIII anchored, in the uncharged group of the phospholipid droplet, factor VIII is converted to VIIIa.

(vii) Similar reactions progress and convert factor $\mathrm{X}$ to $\mathrm{Xa}, \mathrm{V}$ to $\mathrm{Va}$; factor $\mathrm{Xa}$ and $\mathrm{Va}$ convert prothrombin to thrombin with phospholipid and calcium ion. Thrombin converts fibrinogen to fibrin and factor XIII to XIIIa which in presence of calcium ion stabilizes the fibrin into crosslinked fibrin.

In case of extrinsic system factor VII converts to VIIa with tissue factor and calcium ions. The factor VIla converts factor $\mathrm{X}$ to $\mathrm{Xa}$ with similar interactions as described above and further reactions follow as in the intrinsic cascade system. The nature of the protein adsorbed may also affect the activation of blood coagulation, complement and fibrinolytic system. It is also now known that receptors of fibrinogen exist on the platelet surface. Therefore platelets adhere where they find fibrinogen (Marguerie et al 1979); these receptors are available to fibrinogen when ADP is added to a platelet suspension. Therefore much attention has been paid in our laboratory to understand fibrinogen adsorption onto various substrates in comparison to albumin.

The complexity of blood-material interactions at the interface is depicted in figures 1 and 2. Table 1 lists the blood coagulation factors.

Lyman et al (1965) studied several polymer surfaces and evaluated their critical surface tension $\left(\gamma_{\mathrm{c}}\right)$ and surface free energy $\left(\gamma_{\mathrm{s}}\right)$ using contact angle data determined by the method of Zisman (1964). While the initial studies showed a relationship between the rate of clotting and $\gamma_{s}$, later studies indicated that this relationship does not hold rigorously, probably because of the heterogenicity of the surface.

Andrade et al (1973) postulated that material surfaces which tend to have an interfacial energy of zero will be highly thromboresistant. The fact that materials 
Table 1. Coagulation factors.

\begin{tabular}{ll}
\hline Factor & Name \\
\hline I & Fibrinogen \\
II & Prothrombin \\
III & Thromboplastin \\
IV & Calcium ion \\
V & Proaccelerin \\
VI & Not assigned \\
VII & Proconvertin \\
VIII & Antihaemophilic factor \\
IX & Christmas factor \\
X & Stuart factor \\
XI & Plasma thromboplastin \\
& antecedent \\
XII & Hageman factor \\
XIII & Fibrin stabilizing factor \\
\hline
\end{tabular}

\section{Intrinsic system}

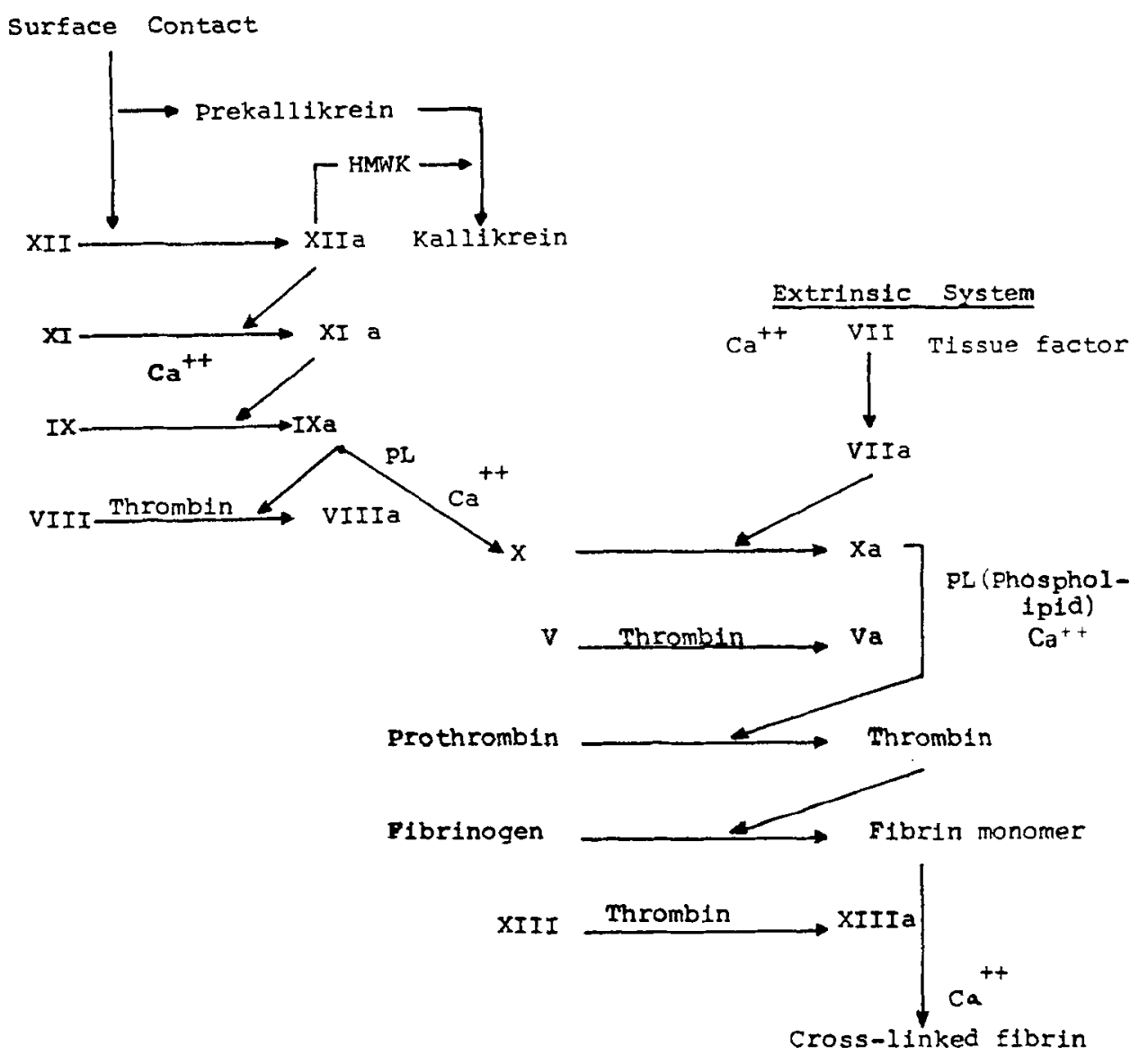

Figure 1. Blood coagulation cascade. 


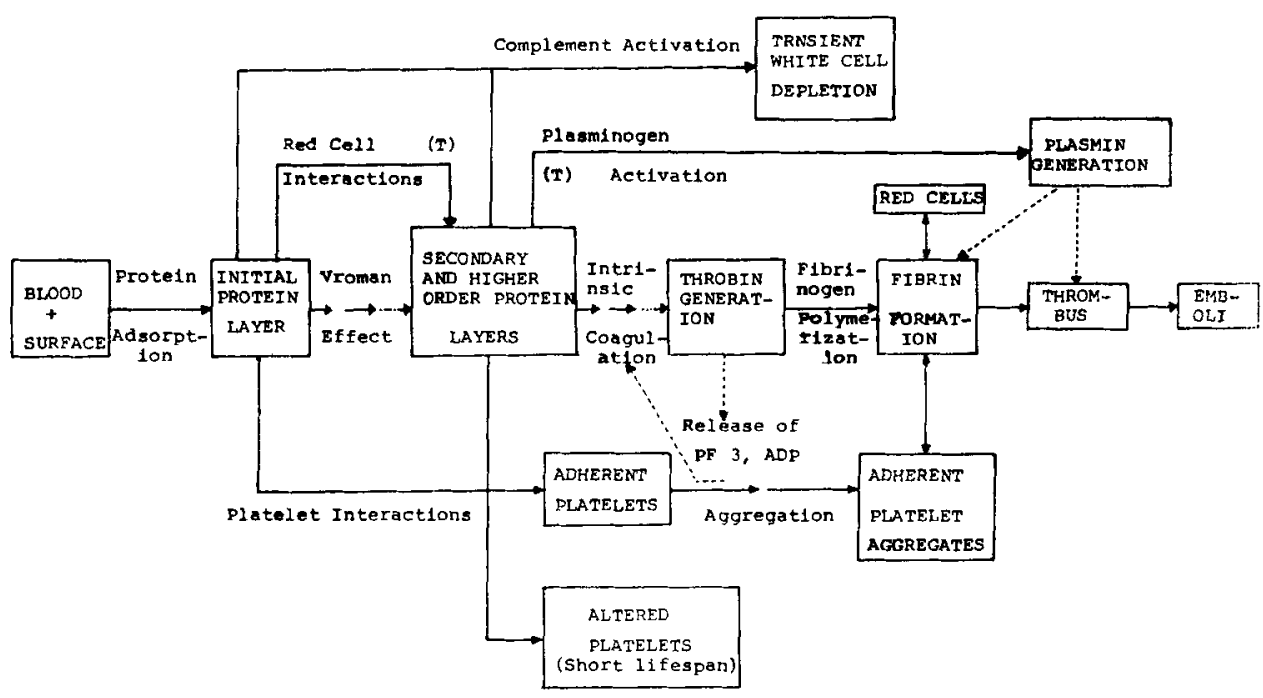

Figure 2. Blood-material interaction sequence.

with a minimal interfacial energy like hydrogels do possess a relatively low thrombus adherence enhances the validity of this hypothesis. Similarly the surface free energies of many polymers have been calculated by contact angle measurement. It was observed that a polymer having a critical surface tension of around $20-30$ dynes $/ \mathrm{cm}$ is highly blood-compatible (Baier et al 1970), but exceptions have been reported as in LTI carbons $\left(\gamma_{\mathrm{c}} \simeq 50\right.$ dynes $\left./ \mathrm{cm}\right)$. Further it has been indicated that dispersion $\alpha_{\mathrm{s}}=\sqrt{\gamma_{\mathrm{s}}^{d}}$ and polar $\beta_{s}=\sqrt{\gamma_{s}^{p}}$ components of polymer surfaces play an important role in interfacial interactions. It was found that low-dispersion, high-polarity surfaces, typified by surface-treated stillite 21 with $\alpha_{\mathrm{s}}=5 \cdot 0(\text { dynes } / \mathrm{cm})^{1 / 2}$ and $\beta_{\mathrm{s}} \geqslant 5.0(\text { dynes } / \mathrm{cm})^{1 / 2}$, provide surface energies that appear to favour weak adsorption and retention of plasma proteins, i.e. a poor surface from the compatibility point of view. Again, high-dispersion, low-polarity implants, e.g. LTI carbon with $\alpha_{\mathrm{s}} \geqslant 6.0(\text { dynes } / \mathrm{cm})^{1 / 2}$ and $\beta_{\mathrm{s}} \leqslant 2 \cdot 0(\mathrm{dynes} / \mathrm{cm})^{1 / 2}$, provide surface energetics favouring stable plasma protein retention, i.e. an excellent surface for blood compatibility (Kaelble and Moacanin 1977). For LTI carbons $\alpha_{\mathrm{s}}$ and $\beta_{\mathrm{s}}$ values are $7 \cdot 38(\text { dynes } / \mathrm{cm})^{1 / 2}$ and $2 \cdot 04(\mathrm{dynes} / \mathrm{cm})^{1 / 2}$. Sharma (1980) suggested an optimum $\alpha_{\mathrm{s}}$ of $4 \cdot 7(\text { dynes } / \mathrm{cm})^{1 / 2}$ and $\dot{\beta}_{\mathrm{s}}$ of $3 \cdot 0(\text { dynes } / \mathrm{cm})^{1 / 2}$ for a possible blood-compatible surface based on experimental observations and theoretical calculations as depicted in table 2. Such surfaces seem to adsorb albumin preferentially on the basis of the dispersion and polar components of the protein interacting with the surface.

The dispersion $\alpha_{\mathrm{s}}$ and polar $\beta_{\mathrm{s}}$ components can be determined for any substrate as suggested by Kaelble and Moacanin (1977) as follows:

$$
\begin{aligned}
& \gamma_{S V}=\gamma_{S V}^{a}+\gamma_{S V}^{p}=\alpha_{S}^{2}+\beta_{S}^{2}, \\
& \gamma_{L V}=\gamma_{L V}^{d}+\gamma_{L V}^{p}=\alpha_{L}^{2}+\beta_{L}^{2} .
\end{aligned}
$$

Adhesion energy, which is basically a measure of interface bonding, is given by

$$
W_{S L}=\gamma_{L V}\left(1+\cos \theta_{L}\right) \leqslant 2 \gamma_{L V}
$$


Table 2. Surface free energy components for various polymers.

\begin{tabular}{|c|c|c|c|c|c|}
\hline Polymer & $\alpha_{\mathrm{s}}$ & $\beta_{\mathrm{s}}$ & $\gamma_{s}$ & $\gamma_{\mathrm{c}}$ & $\gamma_{i j}$ \\
\hline Silastic rubber $(\mathrm{SR})$ & $4 \cdot 4$ & 3.0 & $28 \cdot 4$ & $25 \cdot 5$ & $17 \cdot 2$ \\
\hline SR (Cast) - air & $4 \cdot 6$ & $2 \cdot 1$ & 25.6 & $24 \cdot 0$ & $25 \cdot 4$ \\
\hline SR (Cast) - FEP & $4 \cdot 6$ & $2 \cdot 1$ & 25.6 & $24 \cdot 0$ & $25 \cdot 4$ \\
\hline Polyethylene & $5 \cdot 15$ & $2 \cdot 0$ & 30.5 & $33 \cdot 0$ & $26 \cdot 7$ \\
\hline Polypropylene & $5 \cdot 1$ & 1.75 & $29 \cdot 0$ & $30 \cdot 0$ & $29 \cdot 3$ \\
\hline TPX & $5 \cdot 1$ & $2 \cdot 0$ & 300 & $25 \cdot 0$ & $26 \cdot 6$ \\
\hline 2025 - air & $5 \cdot 2$ & $2 \cdot 3$ & $32 \cdot 3$ & $31 \cdot 5$ & $23 \cdot 7$ \\
\hline 2025 - glass & $5 \cdot 15$ & $2 \cdot 8$ & $34 \cdot 3$ & $31 \cdot 5$ & $19 \cdot 0$ \\
\hline 1025 - air & 4.9 & $3 \cdot 3$ & $34 \cdot 9$ & $31 \cdot 5$ & 14.8 \\
\hline 1025 - glass & 4.9 & 3.5 & $36 \cdot 3$ & 31.5 & $13 \cdot 4$ \\
\hline $710-$ air & $5 \cdot 15$ & $2 \cdot 85$ & $34 \cdot 6$ & $31 \cdot 5$ & $18 \cdot 7$ \\
\hline 710 - glass & $5 \cdot 15$ & $2 \cdot 75$ & $34 \cdot 1$ & $31 \cdot 5$ & $19 \cdot 5$ \\
\hline Biomer - air & $4 \cdot 8$ & $3 \cdot 2$ & $33 \cdot 3$ & $25 \cdot 0$ & $15 \cdot 5$ \\
\hline Biomer - glass & $4 \cdot 8$ & $3 \cdot 2$ & $33 \cdot 3$ & $25 \cdot 0$ & 15.5 \\
\hline
\end{tabular}

TPX, 4-methyl poly - pentene - 1

Block copolymer urethane ureas were based on polypropylene glycols of MW 2025, 1025, 710.

where $\theta_{\mathbf{L}}$ is the contact angle of various organic solvents on the substrates.

$$
\begin{aligned}
& W_{\mathrm{SL}}=2\left[\alpha_{\mathrm{S}} \alpha_{\mathrm{L}}+\beta_{\mathrm{S}} \beta_{\mathrm{L}}\right], \\
& \frac{W_{\mathrm{SL}}}{2 \alpha_{\mathrm{L}}}=\alpha_{\mathrm{S}}+\beta_{\mathrm{S}}\left[\frac{\beta_{\mathrm{L}}}{\alpha_{\mathrm{L}}}\right] .
\end{aligned}
$$

Thus $\left[\frac{W_{\mathrm{SL}}}{2 \alpha_{\mathrm{L}}}\right]$ vs $\left[\frac{\beta_{\mathrm{L}}}{\alpha_{\mathrm{L}}}\right]$ is plotted as a straight line with intercept $\alpha_{\mathrm{S}}$ and slope $\beta_{\mathrm{S}}$. Since $\alpha_{\mathrm{S}}$ and $\beta_{\mathrm{S}}$ are square roots of dispersion $\gamma_{\mathrm{SV}}^{d}$ and polar $\gamma_{\mathrm{SV}}^{p}$ parts of $\gamma_{\mathrm{SV}}$, these components can be evaluated.

Kaelble (1976) further summarized the general concept for regular adsorption bonding in interfaces in the following relation for interfacial tension:

$$
\gamma_{i j}=\left(\alpha_{i}-\alpha_{j}\right)^{2}+\left(\beta_{i}-\beta_{j}\right)^{2}+\Delta_{i j}
$$

Subscripts denote interactions from phase $i$ and $j$ interfaces dominated by van der Waals interactions which are termed as regular interfaces and the values of the term $\Delta_{i i}$ describe interdiffusion or ionic covalent interactions, which can be considered negligible. Thus from known values of $\alpha$ and $\beta, \gamma_{i j}$ values for substrate - protein system can be evaluated as given in table 3 .

From table 3 it seems that the interfacial tension is lowest with albumin in both the cases, viz model surface and LTI carbon, compared to fibrinogen and $\gamma$-globulin. However, LTI carbon with high dispersion and low polar components may interact with all proteins under consideration quite intensely, unlike the case of the model surface, where both the dispersion and polar components appear to be taking an active part in the interaction process for albumin. On the other hand polar components are playing a predominant role in case of fibrinogen and $\gamma$-globulin. So a 
Table 3. Interfacial energy parameters for different proteins and for platelets.

\begin{tabular}{|c|c|c|c|c|c|c|c|}
\hline \multirow[b]{3}{*}{ Protein } & \multirow{3}{*}{$\begin{array}{l}\text { Polar } \\
\text { non- } \\
\text { polar } \\
\text { ratio }\end{array}$} & \multirow[b]{2}{*}{$\alpha_{i}$} & \multirow[b]{2}{*}{$\beta_{i}$} & \multicolumn{2}{|c|}{$\begin{array}{c}\text { Model } \\
\text { substrate }^{\mathrm{a}, \mathrm{c}}\end{array}$} & \multicolumn{2}{|c|}{$\begin{array}{c}\text { LTI } \\
\text { carbon }^{b, c}\end{array}$} \\
\hline & & & & $\gamma_{i j}$ & $\frac{\left(\beta_{i}-\beta_{j}\right)}{\left(\alpha_{i}-\alpha_{j}\right)^{2}}$ & $\gamma_{i j}$ & $\frac{\left(\beta_{i}-\beta_{j}\right)^{2}}{\left(\alpha_{i}-\alpha_{j}\right)^{2}}$ \\
\hline & & {$[$ (dyn } & $\left.(\mathrm{m})^{1 / 2}\right]$ & & $\mathrm{es} / \mathrm{cm})$ & & ynes/cm) \\
\hline Fibrinogen & 1.626 & 4.97 & $6 \cdot 35$ & $11 \cdot 27$ & $151 \cdot 3$ & $24 \cdot 39$ & 3.5 \\
\hline$\gamma$-Globulin & $1 \cdot 205$ & 5.43 & 5.96 & $9 \cdot 30$ & $16 \cdot 8$ & $19 \cdot 20$ & $4 \cdot 4$ \\
\hline Albumin & 1.072 & $5 \cdot 60$ & $5 \cdot 79$ & $8 \cdot 64$ & $9 \cdot 6$ & $17 \cdot 30$ & $4 \cdot 4$ \\
\hline Platelets & 2.604 & $4 \cdot 40$ & $7 \cdot 10$ & 16.90 & $186 \cdot 8$ & 34.48 & $2 \cdot 0$ \\
\hline
\end{tabular}

${ }^{2}$ For values of $\alpha_{j}=4.7(\mathrm{dynes} / \mathrm{cm})^{1 / 2}$ and $\beta_{j}=3.0(\mathrm{dynes} / \mathrm{cm})^{1 / 2}$

${ }^{b}$ For values of $\alpha_{j} \simeq 7.38(\text { dynes } / \mathrm{cm})^{1 / 2}$ and $\beta_{j}=2.04(\text { dynes } / \mathrm{cm})^{1 / 2}$

'The ratio indicates relative contribution of polar to dispersion components toward interfacial energy for the various proteins and for platelets compared for the same surface.

possibility of weak adsorption of these proteins is suggested on this surface relatively (Sharma 1984). In case of LTI carbons, which may interact with all the proteins under discussion equally intensely, taking dispersion and polar components of the proteins into account, no preferential adsorption may be possible. Therefore availability of a particular protein may also be an important parameter in this case. Since albumin content is much higher in blood compared to other proteins, an increased adsorption of albumin on LTI carbons is suggested. Further, albuminated surfaces, as discussed earlier, usually reduce the adhesion of platelets and enhance the blood compatibility. So this may certainly be one of the reasons why LTI carbons are also blood-compatible. Similarly the cell or microbial adhesion onto nonproteinated model surface and LTI carbon can be explained relatively. For example, the dispersion $\alpha_{p}$ and polar $\beta_{p}$ components for platelets has been evaluated (Sharma $1991)$ to be $4.4(\text { dynes } / \mathrm{cm})^{1 / 2}$ and $7 \cdot 1(\text { dynes } / \mathrm{cm})^{1 / 2}$ as shown in table 3 . Obviously, for LTI carbons, there is no preferential adhesion of proteins of platelets (cells), while on model surface, albumin adsorption is preferential even in comparison to platelets.

However, the adhesion of platelets onto various substrates is very complex and certainly not governed by a single specific parameter. It is observed with ${ }^{125} \mathrm{I}$ labelled human fibrinogen or immunoglobulin $\mathrm{G}$ (IgG) that the adsorption of fibrinogen and IgG were greater on polyacrylonitrile than on cuprophane. However, fibrinogenated polyacrylonitrile does not promote the adhesion of ${ }^{51} \mathrm{Cr}$-labelled platelets or polymorphonuclear leucocytes. This may be due to either the direct involvement of fibrinogen-active sites in the interaction of the protein molecule with polyacrylonitrile or a conformational change in the fibrinogen molecule upon adsorption with respect to the surface energy components of the polymer (Chuang et al 1982). Further, fibrinogen has platelet adhering sites and these sites may have different energy parameters, compared to the rest of the segment, suitable to encourage the adhesion of platelets. The human fibrinogen molecule consists of three pairs of peptide chains joined by disulphide bridges. It is observed that platelet adhesion to polycarbonate (PC) substrates is inhibited by addition of fibrinogen factor $2 b,(A \alpha$, $\mathrm{B} \beta)_{2} \gamma \gamma^{1}$, with no significant difference between the effects of fraction la and $\mathrm{lb}$, i.e. $(\mathrm{A} \alpha, \mathrm{B} \beta, \gamma)_{2}$ chain composition. ADP-induced platelet binding to PC substrate also 
decreases in presence of fraction $2 \mathrm{~b}$ (Chandy and Sharma 1987). This may be due to the nonavailability of binding sites on this molecule or because a conformational change in the $\mathrm{COOH}$ terminus of the $\gamma$ chain or $\gamma^{1}$ chain causes a change in fibrinogen conformation itself. On many materials, when blood comes in contact, instant adsorption of fibrinogen takes place, along with activatable clotting factors. Mainly HMWK will displace fibrinogen film within a few minutes. This is difficult in narrow spaces and if dilution is affecting concentration of HMWK or surface-activated blood with insufficient intact HMWK to remove the fibrinogen deposited. In such cases platelet adhesion is promoted. Perhaps while platelets race with fibrinogen/HMWK interactions, granulocytes race with $\gamma$-globulin plasma protein interaction of a similar nature (Vroman 1984-85). It is also observed that the incubation of pure fibrinogen in presence of a trace of plasminogen or plasma considerably enhances the plasmininduced degradation of adsorbed fibrinogen (Brash et al 1985). Further, platelets, cells and proteins tend to have a net negative zeta potential of -8 to $-13 \mathrm{mV}$ (Sawyer and Pate 1953). If the surface is not highly charged, certain proteins, preferably albumin, may be adsorbed and form a passivating layer, which may ultimately make the material less adverse toward blood components and hence relatively more blood-compatible. For highly charged surfaces, even if protein adsorption does not take place, blood components may still suffer damage. For example, activated platelets may aggregate as microemboli and deposit in various organs causing the implant unsuccessful in the long run (Sharma 1991). Further, there also appears to be a relationship between complement activation and leucopenia occurring in haemodialysis with cellulose membranes. It seems that leucocyte adhesion is mediated by complement components. Complement activation via the alternative pathway, when blood comes in contact with implant with activation of $C_{3}$ and $C_{5}$ to $C_{3 a}$ and $C_{5 a}$ respectively, which induce mast cell degranulation resulting in histamine release, also stimulates cytokine (interleukin 1) release from monocytes. Along with cytokine leukotriene $\mathrm{B}_{4}\left(\mathrm{LTB}_{4}\right)$ and platelet activation factor (PAF) enhanced cell adhesion is brought about (including even neutrophil endothelial cell adhesivity). This encourages the formation of superoxide anion, $\mathrm{H}_{2} \mathrm{O}_{2}, \mathrm{OH}$ etc; along with collagenase, elastase, gelatinase etc. These products may inhibit the reendothelialization of bloodcontacting surfaces. It is believed that tissue necrosis factor (TNF) from activated neutrophils also plays an important role in the above process. The understanding of the above concepts is still not complete.

An attempt was made to further understand blood-material interaction by preparing surfaces having similar surface energy by grafting various hydrogels onto Angioflex via ${ }^{60} \mathrm{Co}$ irradiation (Hari and Sharma 1991) as indicated in table 4. It is obvious from the results that the polyethylene glycol-grafted substrate demonstrated not only adsorption of albumin but also less adhesion of platelets. This reflects the relevance of chemical nature of the substrate besides surface free energy parameters. Further, blood-compatible surfaces do not induce morphological changes in platelets (pseudopods), release of serotonin, ADP and platelet factor $\left(\mathrm{PF}_{4}\right)$, etc. Platelets may lose their shape slightly, but come back to original shape if reflected from the substrates (Hari and Sharma 1993).

A similar phenomenon is obvious on biologically modified surfaces as shown in table 5. While octane contact angles are similar, platelet adhesion is low on certain substrates depending upon biological activity.

From the above discussion one can conclude that both physicochemical and 
Table 4. Platelet adhesion, amount of proteins adsorbed after $3 \mathrm{~h}$ exposure, and surface free energy $\left(\gamma_{s v}\right)$ of Angioflex surfaces grafted with various hydrogels.

\begin{tabular}{|c|c|c|c|c|}
\hline \multirow[b]{2}{*}{ Surface } & \multirow[b]{2}{*}{$\gamma_{\mathbf{s v}}$} & \multirow{2}{*}{$\begin{array}{c}\text { No. of } \\
\text { platelets } \\
\text { adhered } / \mathrm{mm}^{2}\end{array}$} & \multicolumn{2}{|c|}{$\begin{array}{l}\text { Surface conc. of } \\
\left(\mu \mathrm{g} / \mathrm{cm}^{2}\right) \pm S . D\end{array}$} \\
\hline & & & Albumin & Fibrinogen \\
\hline Bare Angioflex & 30.98 & $12 \cdot 3 \pm 2 \cdot 3$ & $1.209 \pm 0.17$ & $0.662 \pm 0.11$ \\
\hline Gamma irradiated* & $32 \cdot 10$ & $10 \cdot 0 \pm 2 \cdot 8$ & $1 \cdot 046 \pm 2 \cdot 17$ & $0.697 \pm 0.11$ \\
\hline PHEMA grafted* & $35 \cdot 64$ & $4 \cdot 5 \pm 2 \cdot 0$ & $1.522 \pm 0.15$ & $0.718 \pm 0.12$ \\
\hline $\begin{array}{l}\text { Polyacrylonitrile } \\
\text { grafted* }\end{array}$ & 35.47 & $5 \cdot 0 \pm 1 \cdot 8$ & $1.543 \pm 0.14$ & $0.800 \pm 0.12$ \\
\hline Polyacrylamide & & & & \\
\hline grafted* & $35 \cdot 05$ & $5 \cdot 3 \pm 2 \cdot 0$ & $1.330 \pm 0.11$ & $0.646 \pm 0.12$ \\
\hline PEG grafted* & $35 \cdot 50$ & $2.8 \pm 1.8$ & $1.270 \pm 0.32$ & $0.568 \pm 0.06$ \\
\hline Bare PEUU & - & $6 \cdot 2 \pm 2 \cdot 0$ & $0 \cdot 280$ & $0 \cdot 240$ \\
\hline PE grafted** & - & $1.4 \pm 1.0$ & $0 \cdot 290$ & 0.250 \\
\hline
\end{tabular}

*On Angioflex surface

**Polyelectrolyte (PE) with sulphamate and carboxylate groups like heparin developed from natural rubber (on PEUU surface)

Table 5. Octane contact angle and platelet adhesion to various modified chitosan membranes.

\begin{tabular}{|c|c|c|}
\hline Membrane & $\begin{array}{l}\text { Octane cont- } \\
\text { act angle } \\
\text { (degrees) }\end{array}$ & $\begin{array}{l}\text { Adhered plate- } \\
\text { lets per } \mathrm{mm}^{2} \\
\pm \text { S.D. }\end{array}$ \\
\hline \multicolumn{3}{|l|}{ Albumin-blended } \\
\hline chitosan membrane (ACM) & $138.2 \pm 2.44$ & $17 \cdot 7 \pm 2 \cdot 00$ \\
\hline ACM + liposome $(+$ ve $)$ & $134 \cdot 1 \pm 2 \cdot 70$ & $25 \cdot 7 \pm 2 \cdot 60$ \\
\hline $\mathrm{ACM}+$ lip. $(+\mathrm{ve})+$ hirudin & $141 \cdot 3 \pm 1 \cdot 60$ & $12 \cdot 5+2 \cdot 00$ \\
\hline$A C M+$ lip. $(+$ ve $)+\mathrm{PGE}_{1}$ & $122 \cdot 3 \pm 3 \cdot 17$ & $8 \cdot 3 \pm 1 \cdot 80$ \\
\hline ACM + lip. $(+$ ve $)+A T-I I I$ & $138.5 \pm 1.44$ & $11.7 \pm 1.90$ \\
\hline $\mathrm{ACM}+$ lip. $(+$ ve $)+$ heparin & $137.1 \pm 1.81$ & $10 \cdot 5 \pm 2 \cdot 10$ \\
\hline ACM + liposome $(-$ ve $)$ & $141.4 \pm 2.30$ & $15 \cdot 0 \pm 2 \cdot 3$ \\
\hline ACM + lip. $(-$ ve $)+$ hirudin & $143 \cdot 7 \pm 2 \cdot 10$ & $10.2 \pm 1.98$ \\
\hline$A C M+$ lip. $(-v e)+P G_{1}$ & $133.4 \pm 2.07$ & $5.9 \pm 1.95$ \\
\hline$A C M+$ lip. $(-$ ve $)+A T-I I I$ & $143.6 \pm 2.06$ & $9.8 \pm 1.93$ \\
\hline$A C M+$ lip. $(-$ ve $)+$ heparin & $144 \cdot 2 \pm 1 \cdot 35$ & $9 \cdot 3 \pm 1.91$ \\
\hline
\end{tabular}

AT-III, antithrombin III.

biological aspects are important while considering blood-material interaction with an objective of developing blood-compatible material surfaces. Surface modification by immobilizing antithrombin III, $\mathrm{PGE}_{1}$ and methyldopa complex on albuminated substrates has also been attempted, which demonstrated enhanced albumin adsorption compared to bare PC surface (Chandy and Sharma 1989). Similarly aspirin, vitamins, antibiotics, anaesthetics, antihypertensive drugs, etc seem to encourage albumin adsorption in varied degree and also reduce platelet adhesion. This could 
be important information from the clinical point of view for patients having an artificial internal organ (Sharma 1991).

Usually in case of polymers the denatured protein-polymer-water system represents a lower energy system than the original state. In case of metals, whether or not an oxide layer is present, there is a large electric field. Small ions accumulate, lowering the strength of the field, but there is a great advantage in replacing these with protein molecules. The dipole moment of a protein is very much greater than that of a small ion and there is a gain in entropy on replacing several small ions by one large molecule. However, denaturation of a protein is not normally experienced in electric fields as the possible loss of free energy is increasing further the dipole moment is rarely greater than the gain due to exposure of the hydrophobic core. Electrostatic and hydrogen bond interactions are other major forces that bind proteins depending upon microenvironment.

Protein adsorption studies on various metal surfaces such as $\mathrm{Ti}, \mathrm{Al}$ and $\mathrm{Ta}$ have been carried out as shown in table 6 . It is interesting to note that after a certain optimum thickness $A \mathrm{l}(500 \AA)$ and Ti $(400 \AA)$ become more blood-compatible, while Ta $(200 \AA)$ becomes tissue-compatible based on Fib/Alb mole ratio (table 6).

Table 6. Protein adsorption onto titanium, tantalum and aluminium with oxide layer of varied thickness.

\begin{tabular}{|c|c|c|c|c|}
\hline \multirow[b]{2}{*}{ Surface } & \multirow{2}{*}{$\begin{array}{l}\text { Water } \\
\text { contact } \\
\text { angle } \\
\text { (degrees) }\end{array}$} & \multicolumn{2}{|c|}{$\begin{array}{l}\text { Protein adsorbed } \\
\text { in } 3 \mathrm{~h}\left(\mu \mathrm{g} / \mathrm{cm}^{2}\right)\end{array}$} & \multirow{2}{*}{$\begin{array}{l}\text { Mole ratio } \\
\text { Fib/Alb }\end{array}$} \\
\hline & & Albumin & Fibrinogen & \\
\hline \multicolumn{5}{|l|}{ I. Titanium ${ }^{1}$} \\
\hline $\begin{array}{l}\text { (a) Cleaned and glow } \\
\text { discharged }\end{array}$ & $21 \cdot 4+1 \cdot 4$ & 0.037 & 1.086 & $5 \cdot 64$ \\
\hline $\begin{array}{l}\text { (b) With } 266 \AA \\
\text { oxide layer }\end{array}$ & $109 \cdot 3 \pm-1 \cdot 8$ & 0.215 & 1.629 & $1 \cdot 44$ \\
\hline (c) "408 $\AA "$ & $117.0 \pm 3.2$ & $0 \cdot 180$ & 1.080 & $1 \cdot 14$ \\
\hline (d) “1268 $\AA "$ & $136 \cdot 3 \pm 6 \cdot 1$ & 0.174 & 0.876 & 0.69 \\
\hline \multicolumn{5}{|l|}{ II. Tantalum ${ }^{2}$} \\
\hline $\begin{array}{l}\text { (a) Cleaned and glow } \\
\text { discharged }\end{array}$ & Spreading & 0.224 & $0 \cdot 228$ & $0 \cdot 186$ \\
\hline $\begin{array}{l}\text { (b) With } 200 \AA \\
\text { oxide layer }\end{array}$ & $60 \cdot 1 \pm 2 \cdot 9$ & 0.127 & 0.272 & 0.391 \\
\hline (c) " $500 \AA ̊ "$ & $50.4 \pm 2.9$ & $0 \cdot 193$ & 0.295 & 0.279 \\
\hline (d) "960 $\AA "$ & $40 \cdot 2 \pm 5 \cdot 7$ & $0 \cdot 248$ & $0 \cdot 388$ & $0 \cdot 286$ \\
\hline \multicolumn{5}{|l|}{ III. Aluminium ${ }^{3}$} \\
\hline $\begin{array}{l}\text { (a) Cleaned and glow } \\
\text { discharged }\end{array}$ & Spreading & 0.041 & 0.060 & $0 \cdot 268$ \\
\hline $\begin{array}{l}\text { (b) With } 50 \AA \\
\text { oxide layer }\end{array}$ & $26 \cdot 2 \pm 7.8$ & 0.065 & $0 \cdot 120$ & 0.338 \\
\hline (c) "350 $\AA "$ & $33 \cdot 1 \pm 2 \cdot 2$ & 0.072 & $0 \cdot 130$ & 0.331 \\
\hline (d) " $500 \AA "$ & $34.2 \pm 6.6$ & 0.089 & $0 \cdot 140$ & $0-288$ \\
\hline (e) $" 840 \AA "$ & $31 \cdot 7 \pm 4 \cdot 7$ & 0.070 & 0.130 & $0 \cdot 340$ \\
\hline
\end{tabular}

1. Sunny and Sharma (1991)

2. Sharma and Paul (1992)

3. Sunny and Sharma (1990); Sharma and Sunny (1990) 
Problems related to T-cell defects cause autoimmune disease due to overproduction of antibodies by B-cells (up to two to three times more than normal). To help such patients, usually the blood is fractionated via plasmapheresis and plasma is passed through a perfusion column where selected adsorption of pathogenic immunoglobulins occurs. After passing through this column the plasma along with other blood components is passed into the patient. An attempt was made utilizing polyvinyl alcohol (PVA), chitosan, polyacrylamide (PAA) and hydroxyapatite (HA) $(200-400 \mu)$ beads modified with amino acids such as tryptophan and phenylalanine for selective adsorption of immunoglobulins from whole blood if possible. The results appear to be encouraging as shown in table 7 .

Since bone consists of collagen and $\mathrm{HA}(60-70 \%)$, the latter, $\mathrm{Ca}_{10}\left(\mathrm{PO}_{4}\right)_{6}(\mathrm{OH})_{2}$, was synthesized from $\mathrm{Ca}(\mathrm{OH})_{2}$ and orthophosphoric acid $\mathrm{H}_{3} \mathrm{PO}_{4}$ as basic component. The microspheres of HA have also been developed by the simple procedure of mixing HA with chitosan in acetic acid and dropping this solution slowly into a polymer solution in toluene. By washing the spheres with toluene, acetone and distilled water and heating at $400^{\circ} \mathrm{C}$, the coated chitosen was removed. Such microspheres, of varied sizes and shapes, under pressure with sintering for required porosity may be useful in various dental, orthopaedic and drug-delivery applications. HA-aluminachitosan microspheres have also been developed for similar applications.

Various materials such as PEUU, PVA, chitosan, etc have been used towards artificial-skin applications with and without collagen. In vivo experiments on rabbits (dorsal region) have been performed and relative healing has been evaluated as indicated in table 8 . It is obvious that chitosan can be a very good substitute in artificial-skin application.

The basic problem with bioprosthetic heart valves such as porcine valve (Carpentier Edwards) and bovine pericardium valve (Ionescu-Shiley) has been calcification. However, by treating with $\mathrm{Fe}^{3+}$ or $\mathrm{Al}^{3+}$ solutions it seems that the process of calcification can be inhibited. Even cross-linking agents such as carbodiimide or glycerol etc instead of glutaraldehyde, reduce calcification. Prevention of calcification through $\mathrm{FeCl}_{3}$ release from chitosan beads, coimplanted on subdermal pouches of rats, have been studied in our laboratory. It seems that an optimum combination of ferric and magnesium ions also reduces calcification. A beginning has also been made towards the use of chitosan along with liposome encapsulation systems for significant reduction of calcification in bioprosthetic valves.

Table 7. Immunoprotein adsorption from human plasma (GBS) on modified chitosan (CB), polyvinyl alcohol (PVA) and acrylamide (PAA) microspheres.

\begin{tabular}{|c|c|c|c|c|c|c|c|}
\hline \multirow[b]{2}{*}{ Protein } & \multirow{2}{*}{$\begin{array}{l}\text { Pre-perfusion } \\
\text { levels }(\mathrm{mg} / \mathrm{dL})\end{array}$} & \multicolumn{3}{|c|}{ Post-perfusion level (mg/dL) } & \multicolumn{3}{|c|}{$\begin{array}{l}\text { Percentage } \\
\text { adsorbed }\end{array}$} \\
\hline & & CB & PVA & PAA & CB & PVA & PAA \\
\hline $\lg G$ & 763.81 & $589 \cdot 59$ & $679 \cdot 11$ & 666.55 & $22 \cdot 8$ & $11 \cdot 1$ & $12 \cdot 7$ \\
\hline IgM & 90.88 & $81 \cdot 74$ & 83.57 & 79.00 & $10 \cdot 1$ & $8 \cdot 1$ & $13 \cdot 1$ \\
\hline IgA & 147.27 & 70.81 & 95.95 & $98 \cdot 20$ & 51.9 & 34.8 & $33 \cdot 3$ \\
\hline $\mathrm{C}_{3}$ & $200 \cdot 06$ & $162 \cdot 86$ & 139.04 & $176 \cdot 30$ & $18 \cdot 6$ & 30.5 & 11.9 \\
\hline
\end{tabular}

Adsorption was for $3 \mathrm{~h}$ on $3 \mathrm{~g}$ of microspheres (bead size CB $400-600 \mu \mathrm{m}$ ). GBS, Guillain Barre syndrome (PAA and PVA $600-800 \mu \mathrm{m}$ ). 
Table 8. Wound healing pattern in rabbits of different polymeric samples with various modifications.

\begin{tabular}{lcc}
\hline Sample & Sterilization & $\begin{array}{c}\text { No. of days taken } \\
\text { for complete wound } \\
\text { healing* }\end{array}$ \\
\hline PEUU & Chemical & $36 \cdot 38 \pm 3 \cdot 90$ \\
$\begin{array}{l}\text { PEUU + collagen }+ \\
\text { albumin }\end{array}$ & Chemical & $25 \cdot 15 \pm 4 \cdot 32$ \\
$\begin{array}{l}\text { Albumin + epidermal } \\
\text { growth factor }\end{array}$ & Chemical & $24 \cdot 39 \pm 3 \cdot 83$ \\
PVA & Chemical & $34 \cdot 87 \pm 4 \cdot 12$ \\
PVA + collagen + & Chemical & $38 \cdot 10 \pm 1 \cdot 27$ \\
albumin & Steam & $32 \cdot 74 \pm 5 \cdot 23$ \\
Chitosan & Steam & $24 \cdot 93 \pm 4 \cdot 30$ \\
Chitosan + collagen & Steam & $28 \cdot 81 \pm 8.39$ \\
Chitosan + fibrin gel & & \\
\hline
\end{tabular}

*Each value expressed as mean \pm S.D. of three animals (6 wounds, $3 \times 1.5 \mathrm{~cm}^{2}$ )

\section{Conclusion}

Surface modification of implants plays an important role in enhancing blood and tissue compatibility. However, many surfaces may change after sterilization so emphasis should also be given to understanding sterilization-induced changes in the functioning of any prosthetic device, in vitro and in vivo, before review by an ethics committee for selection for limited clinical trials on humans.

Further, controlling the surface properties at the manufacturing stage alone is not enough because changes may come even at stages like handling, packaging and storage, besides sterilization, which can significantly modify the surface properties and ultimately the success of the implant.

\section{Acknowledgements}

The author wishes to thank his colleagues and staff who have been associated with him for the past fourteen years in progress in the area of biosurface technology. Parts of the work reported have been supported by DBT, DST, ICMR and BRNS, New Delhi. The help of Mr Willi Paul in the preparation of this manuscript is also appreciated.

\section{References}

Andrade J D, Lee H B, John M S, Kim S W and Hibbs J B 1973 Trans. Am. Soc. Artif. Organs 191 Baier R E, Gott V L and Feruse A 1970 Trans. Am. Soc. Artif. Organs 1650 Bonne C, Martin B, Watada M and Regnault F 1981 Thromb. Res. 2113 Brash J L, Chan B M C, Szota P and Thibodeau J A 1985 J. Biomed. Mater. Res. 191017 
Chandy T and Sharma C P 1987 Polym. Plast. Technol. Engg. 26143

Chandy T and Sharma C P 1989 Artif. Organs 13229

Chandy T and Sharma C P 1991 J. Biomed Mater. Res. 251085

Chuang H Y K, Sharpton T R, Mohammed S F, Sharma N C and Mason R G 1982 VII Int. Congress on Thrombosis and Haemostasis THHADO 46304

Forbes C D and Prentice C R M 1978 Brit. Med. Bull. 34201

Hari P R and Sharma C P 1991 J. Biomater. Appl. 6170

Hari P R, Ajith Kumar B and Sharma C P 1993 J. Biomater. Appl. 8174

Ito Y 1992 in Synthesis of biocomposite materials (ed.) Y Emanishi (Bola Raton: CRC Press) pp. 285-305

Kaelble D H 1976 SAMPE Q. 730

Kaelble D H and Moacanin 1977 J. Polym. 18475

Kim S W and Lyman D J 1973 Polym. Symp. 22 (New York: John Wiley \& Sons) pp. 289-297

Lyman D J, Brash J L, Chalkin Klein K G and Carini M 1968 Trans. Am. Soc. Artif. Int. Organs 14250

Lyman D J, Muir W M and Lee I J 1965 Trans. Am. Soc. Artif. Organs 11301

Marguerie G A, Plow E F and Edington T S $1979 \mathrm{~J}$. Polym. Chem. 25453

Moncada S and Vane J R 1979 Fed. Proc. 3866

Rigby B J 1961 Biochim. Biophys. Acta 113472

Rusk S D 1979 J. Polym. Sci., Polym. Symp. 66283

Sawyer P N 1984-85 Biomater. Med. Dev. Artif. Organs special issue on blood compatibility 12 161-196

Sawyer P N and Pate J W 1953 Surgery 34491

Sharma C P 1980 J. Sci. Ind. Res. 39453

Sharma C P 1983 Curr. Sci. 521057

Sharma C P 1984 J. Coll. Interface Sci. 97585

Sharma C P 1991 in Blood compatible materials and devices (ed.) C P Sharma and M Szycher (Massachusetts: Technomic Pub. Co) pp. 25-31

Sharma C P and Nair A K 1984 Trans. Biomater. April 27th-May 1 p. 100

Sharma C P and Paul W 1992 J. Biomed. Mater. Res. 261179

Sharma C P and Sunny M C 1990 Biomaterials 11255

Shayani V, Newman K and Dichek D 1992 Proc. Cardiovascular Science and Technology Conf. AAMI/NH LBI p. 53

Sunny M C and Sharma C P 1990 J. Biomed. Mater. Res. 24455

Sunny M C and Sharma C P 1991 J. Biomater. Appl. 689

Tolia J T and Sharma C P 1986 Trends Biomater. Artif. Organs 17

Urry D W, Nicol A and Hoban I D 1992 Proc. Cardiovascular Science and Technology Conf. AAMI/NHLBI p. 155

Vroman L 1984-85 Biomater. Med. Devices Artif. Organs 121307

Vroman L and Adams A L 1971 J. Polym. Sci. 34159

Williams D F (ed.) 1987 Definitions in biomaterials (New York: Elsevier)

Zisman W A 1964 American Chemical Soc. Series 43, chapter I 